\title{
Retraction
}

\section{Retraction: Savine and Braver, Motivated Cognitive Control: Reward Incentives Modulate Preparatory Neural Activity during Task-Switching}

The Journal of Neuroscience has received the findings of the Office of Research Integrity of the Department of Health and Human Services, which report substantial data misrepresentation in the article "Motivated Cognitive Control: Reward Incentives Modulate Preparatory Neural Activity during Task-Switching" by Adam C. Savine and Todd S. Braver, which appeared on pages 10294-10305 of the August 4, 2010 issue. Because the results cannot be considered reliable, The Journal is retracting the paper.

DOI:10.1523/JNEUROSCI.1696-13.2013 